\title{
Entrance Gate for Germs Challenges in Dealing with Catheters
}

\author{
Elvira Habermann ${ }^{1 *}$, Karin Meyer ${ }^{2}$ \\ ${ }^{1}$ RN Freelance Continence and Stoma Care Nurse \\ ${ }^{2}$ M.Ed. RN Continence and Stoma Care Nurse, Stomaambulanz Klinikum am Wörthersee
}

DOI: $10.36348 /$ sjm.2020.v05i04.010 | Received: 09.04.2020 | Accepted: 19.04.2020 | Published: 30.04 .2020

*Corresponding author: Elvira Habermann, RN

\section{Abstract}

Every catheter always represents a port of entry for pathogens. As a result, a catheter-related urinary tract infection can develop (see Liedl 2017, p. 28) which in the worst case leads to urosepsis (see Norsworthy, Pearson 2017, p. 305; Bublak 2016, p. 17).

Keywords: Permanent Catheter - Urinary Tract Infection - Proteus Mirabilis - Encrustation - Catheter Blockages.

Copyright @ 2020: This is an open-access article distributed under the terms of the Creative Commons Attribution license which permits unrestricted use, distribution, and reproduction in any medium for non-commercial use (NonCommercial, or CC-BY-NC) provided the original author and source are credited.

\section{INTRODUCTION}

Each catheter always also represents an entry point for bacteria. This can cause a catheter-associated urinary tract infection [2], which, in the worst case, leads to urosepsis [3, 4]. Carers are continuously confronted with this problem.

In case of transurethral bladder catheters, bacteria can enter the bladder on three different paths:

- during insertion from the area of the meatus and the distal urethra

- between the urethral catheter and mucous membrane

- by way of retrograde protraction from a contaminated urine collection bag or urethral catheter after disconnection of the closed urine diversion system or at the use of an unsuitable system [5].

Blockages of the catheter, fistulae, stenosis and strictures are further disadvantages of cathetersupported urinary diversion. "Next to a bacterial component, the multifactorial pathogenesis of catheterassociated urinary tract infection and its complications can also exhibit a chemical and mechanical component:

- The catheter surface causes a mechanical irritation of the urothelial. The pressure of the catheter on the mucous membrane leads to local vascular disorders, which cause weakening of the microbial immune status of the mucous membrane.

- The catheter hampers the secrete flow of urethral glands.
- So-called "mucopurulent membranes" or biofilms were the result of retained secretions and cell detritus, function as a medium and conduit for extra-canaliculus ascending bacterial infections.

- Substances emitted from the catheter material, such as so-called emollients, lead to a chemical irritation of the urethra epithelia.

- Surface incrustations on the catheter material promote the formation of biofilm as an adhesive base for bacteria, cell detritus and secretions and cause additional mechanical irritation of the mucous membrane. "Final condition of a scarred fibrotic inflammation (urethritis) is the urethral stricture" [5].

Bacteria in the urine, such as proteus mirabilis, produce an enzyme named urease. This enzyme splits urea into ammonia and carbon dioxide. The process leads to an increase of the $\mathrm{pH}$ value in the urine, which therefore becomes alkaline and thus finds ideal conditions for the development of crystals, such as magnesium ammonium phosphate and calcium phosphate [3, 6]. Liedl describes an experimental discovery that the acidification in the presence of urease leads to an initial decline of the $\mathrm{pH}$ value which, however, quickly returns to the original alkaline value with the further addition of acid. Acidification at a $\mathrm{pH}$ value of 8-9 causes the massive activation of the urease activity, which is detrimental and ineffective for the patient [7]. Thus, incrustations are not prevented, but promoted. 
The bacteria proteus mirabilis with high urease activity is the main cause of persistent incrustation. These are mineralised bacterial biofilms. The urease of this bacterium hydrolyses urea six to ten times faster than the urease of other species. The differentiation of proteus mirabilis in "swarming cells" also plays a role in catheter-associated urinary tract infections, as these spread quickly over the surface. In fact, proteus mirabilis could be detected in the obstructing material of almost all catheters [2]. Incrustations, which can encase the catheter surface and tip, and which form high sediment columns in the lumen, cause the blockage of the permanent catheter. Frequent catheter changes are the result if the bacteria are not treated correctly. Liedl describes this as a so-called blocker which triggers a catheter obstruction with a rising urinary tract infection within a few days [3]. Incrustations cause pain for the catheter patient as well as huge costs for the health system. Because often, the catheter change is not carried out by general practitioners, urologists or care personnel on site, but at the urological outpatient care.

\section{Management of urine drainages Urine diversion system}

The primary contemplation should be whether the catheter patient requires "mobile" diversion at all. If yes, a sterile leg bag has to be connected. According to the Federal health gazette [8] and AWMF [5] only sterile, closed urine diversion systems are to be used. In case of bed-ridden patients or for the transfer in a wheelchair, a sterile, closed urine drainage system with a capacity of two litres and drain cock has to be used. It has a urine sample extraction point, a drip chamber with bacterial-proof ventilation and membrane check valve as well as a longer deviation hose and is thus suitable to be worn for longer periods.

The following characteristics are indispensable:

- $\quad$ free flow = no kinking, no formation of loops

- no tension on the hose

- no contact with the floor for bag or drainage nozzle

- installation below bladder level

- evacuation before urine reaches return-flow blockage

Excessive manipulation at the drainage system rapidly causes intra-luminary bacteria ascension. This results in an almost 100 percent bacteriuria as early as after four days [7]. Madersbacher and Stoces describe that the catheter system has to be sterile, closed and provided with a drainage device [9].

\section{Change cycle of the urine diversion system}

Neither literature nor practical experience contains a generally uniform procedure for drainage systems. The change cycles have to be prescribed by the companies based on the ProdhaftG (Product Liability Act). For example, the average maximum wearing period for sterile leg bags is three days. Unsightliness and odours due to deposits should not be disregarded, as this represents a strong limitation for person participating in an active social life.

As a general rule, the point of connection has to be wiped with a sterile alcohol swab and the impact time must be adhered to [8]. The use of reducible sterile leg bag in the extramural setting has to be scrutinised. Sterile scissors are required In order to reduce the drainage hose properly to the desired length, which are generally not available. The non-sterile night bag is plugged into the drain cock, and detached, evacuated and discarded the next morning. A further variation of diversion for the mobile patient is the sterile catheter valve. It is changed together with the catheter. It provides the option of being free from a urine bag during the day. A bag with sufficient volume can be attached in order to sleep through the night.

According EAUN, a catheter valve is contraindicated at:

- cognitive limitations

- overactive bladder syndrome

- vesicoureteral reflux

- limited bladder capacity

Prior to using a catheter valve, it must be ensured that the person empties the bladder on a regular basis. "When a catheter valve is used, a two to fourhourly release is recommen-ded" (https://nurses.uroweb.org/guideline/catheterisation-in dwelling-catheters-in-adults-urethral-and-suprapubic/ 01.03.2019, p. 33).

\section{Catheter change cycle}

The instruction to change the catheter "when required" is found frequently. The industry prescribes a maximum insertion period, such as with the Teleflex Rüsch Silicon Catheter (six weeks). Accordingly, individual change intervals are to be determined during this period - also in the opinion of practicing experts, i.e. symptom-oriented catheter changes instead of rigid catheter change intervals [2]. The first change should not be made only at the onset of problems, as the removal of an encrusted catheter tip covered in crystals cannot only be painful, but can also lead to injuries of the urethral mucosa. The subsequent catheter change cycle should be determined depending on the condition of the catheter tip and/or the lumen. The focus should be on the object of extending the life cycle of a catheter. The expression "if required" has to be precisely defined in individual cases. "There is no uniform standard for the catheter change intervals. They depend on the characteristics of the material, the diuresis, the infect situation and the tendency for incrustation [10]". Furthermore, unpleasant odours are generated due to biofilms and deposits after approx. four weeks. This can also be rather limiting for the patient in terms of their participation in the social life. It is important to 
ascertain why the permanent catheter was initially applied. Unfortunately, the reasons for this are not always comprehensible. Particularly in case of patients who are in need of care, the catheter - when once installed - remains in situ and is changed again and again. Following an anamnesis and establishment of the illness, an attempt of a catheter outlet should be made between physician and care person, if possible. If this is followed by spontaneous miction, a residual urine control should be performed to determine whether the miction was the result of overflow. The residual urine control should be repeated several times and occur preferably in the afternoon, as practice has shown that the remaining urine increases during the course of the day, which can result in a nightly renal shutdown. If urine is lost next to the catheter, the cause is not an insufficient Charrière or insufficiently blocked catheter. The causes can be spasms of the bladder - these occur due to an irritation and/or a urinary tract infection - or the relocation of the catheter eyes.

\section{CARE}

\section{General information}

Excessive cleansing not only removes contamination, bacteria, sweat and skin scales, but also important structures of the skin such as surface lipids, epidermal (bacteria)lipids and proteins. The skin can dehydrate due to the application of incorrect cleansing products (irritating surfactants). Dry skin (xeroderma) is characterised by reduced moisture content and impaired lipid formation of the corneal layer [11]. "Dry skin can turn into a dehydration eczema (exsiccation eczema), which leads to itchiness. [...] This coincides with an impaired permeability barrier of the skin, evident as reduced repair capability after stress to the skin[12]."

\section{Catheter maintenance}

The daily cleansing of the urethral orifice, catheter and genital region and/or the vicinity in the context of general personal hygiene (with water and soap solution, without the addition of antiseptic substances) is entirely sufficient. Octenisept is only applied for pre-disinfection when the catheter is applied. A regular application for catheter maintenance leads to massive skin irritations and therefore has to be omitted. As the other products in the market approved as disinfection solutions for mucosa contain iodine for pre-disinfection, the use of, for example, Prontoderm $C$ should be considered in case of an incompatibility with Octenisept. It is based on polyhexanide and is an antimicrobial cleansing solution for skin and mucosa not a medical product and not an approved disinfection solution for mucosa. It acts antimicrobial against bacteria incl. MRSA, ORSA, VRE and can specifically be used for the cleaning of the urethra entry prior to the catheterisation if the above-mentioned products are out of the question [5]. Catheter clamping for bladder training prior to the removal of the catheter is obsolete and may increase the frequency of catheter-associated infections [8]. As a consequence, also the clamping of an installed permanent catheter for the purpose of socalled bladder training has to be omitted. "The intermittent clamping of a transurethral indwelling catheter prior to its removal to increase bladder capacity and/or restore normal a miction rhythm (so-called bladder training) initiates infection complications and should be omitted. Routine irrigation has not proven to be effective [2]".

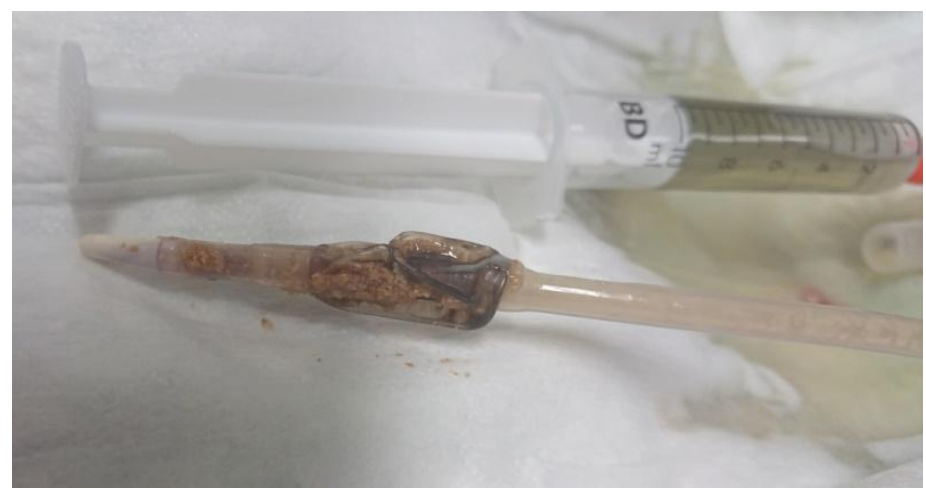

\section{INCRUSTATIONS Clarification}

According to Radmayr, bacterial colonisation occurs within a very short time after the installation of a catheter. This, in turn, consequentially increases the risk of encrustation in the catheter and ultimately leads to its blockage [13].

In case of multiple catheter blockages with frequently necessary catheter changes and subjective complaints, such as
- $\quad$ pain in the bladder area - caused by the reduced flow and the chafing of the crystals on the bladder mucosa,

- urge to urinate, in men generally evident in the tip of the penis, a urine culture and resistance determination should be initiated. Most specimens exhibit the bacteria proteus mirabilis [7].

\section{Therapy}

In order to prevent incrustation in the abovementioned criteria in the long term, a targeted antibiotic therapy for a sufficiently long period of time should be 
prescribed. In case of a symptomatic urinary tract infection and installed permanent catheter, an antibiotic therapy without an immediate catheter change is not sufficient, but often leads to failure or even death [7]. In the event of a catheter-associated urinary tract infection, the catheter has to be changed, if possible, at the start and/or at least during the course of the antibiotic therapy [8], as bacterial biofilms form even after a very short period of time following installation. However, this occurs rather rarely in practice. "A lack of clinical improvement within the first three days after the start of the therapy or a recurrence of the symptoms within the first two weeks has to result in a re-evaluation of the therapy. A lack of compliance by the patient, resistance of the pathogen or unconsidered complicating factors have to be taken into account as a cause. A renewed urine examination incl. urine culture and resistance testing as well as the change of the antibiotics are indicated in this case. The improvement of the symptoms and the negative urine findings as a followup is indications of the success of the therapy[14]".

\section{Bladder irrigation}

Irrigations and instillation via the installed catheter are only conducted in case of special urological indications due to the risk of infection. In this case particularly in the external area - reasonably realisable irrigation intervals have to be determined. The first measure should be "internal" irrigation by way of sufficient fluid intake: urination of $1.5-21 / 24 \mathrm{~h}$ would be optimal. Also the position of the catheter and/or the drainage should be inspected with respect to kinks. Complications may occur if irrigation is performed with a bladder syringe and sterile $\mathrm{NaCl}$ solution in case of catheter blockages. These begin as early as with the handling of loading and furthermore with the disconnecting of the urine drainage. Furthermore, incrustations can be flushed into the bladder and settle on the floor of the bladder, i.e. predominately below the blocked balloon. Therefore, there are various sterile ready-made disposable irrigation solutions (individually packaged and sealed), which are to be used based on indications according to the physician's instructions (as e.g. Uro-Tainer).

\section{Irrigation solutions}

Uro-Tainer $\mathrm{NaCl} 0.9 \%$ is designed for the application in case of tissue residues, mucous and minor blood deposits. This is a purely mechanical effect. Apply as required. Uro-Tainer Suby $G$ (citric acid 3.23 $\%)$ is a mild, hypotonic solution which causes less irritation due to the addition of magnesium. The solution was especially developed to prevent phosphate crystal formation and to dissolve existing calcifications in case of permanent catheters. The reaction time is five minutes. In the process, attention should be paid to subjective irritations. This irrigation dissolves incrustation, reduces the $\mathrm{pH}$ value and minimises bioburden in the bladder. Application up to twice daily, if required. Uro-Tainer PHMB (0.02\% polyhexanide) serves to prevent Catheter Associated Urinary Tract Infection (CAUTI), reduces bacterial colonisation on catheter and bladder and achieves a reduction of the biofilm by $87 \%$ compared to irrigation with $\mathrm{NaCl}$. This irrigation is applied supplementary to systemic treatment in case of a bladder infection. If left in the bladder for a prolonged period of time, a burning sensation can occur; therefore, immediate drainage without reaction time has to be adhered to. Application up to twice daily. Freka Drainjet $\mathrm{NaCl} 0.9 \%$ is an isotonic sodium chloride solution and serves for the drainage and cleansing of the extracorporeal circulation of haemodialysis systems as well as the intra- and postoperative bladder irrigation during urological surgery. Freka Drainjet Solutio $R$ plus is a rinsing solution that can be used during surgical and medical interventions for the rinsing and cleansing of anatomic structures. Suitable for the irrigation of the bladder and permanent catheters to prevent and eliminate catheter incrustations. It contains magnesium hydroxyl-carbonate, citric acid, D-Glucono-1.5-lacton, Magnesium citrate and water for injection purposes. Irritations, inflammations, pain or camps can occur due to the citric acid concentration. Here, a reaction time of 20 minutes is described. Apply up to twice daily. One point worthy of note is that this product is not packaged sterile and individually. Although the rinsing agent is sterile, the connector incl. screw stopper is merely provided with a perforated protection cap. Due to the harmonica principle, the risk of an uncontrolled vacuum exists. This can lead to micro lesions of the urogenital mucous membranes.

\section{Alternative measures}

Antibiotic-resistances represent an increasing problem in the treatment of urinary tract infections. New alternative therapy approaches can possibly provide relief in this matter. In a study, 476 patients, who suffered acute, uncomplicated urinary tract infection, were treated with a combination preparation made of nasturtium and horseradish root (3-5 capsules/day). This revealed that the efficacy is comparable with that of the standard antibiotics, yet the compatibility was significantly better. Extracts from birch leaves, horsetail herb, smooth rupture wort, sweet woodruff, stinging nettle and cranberry leaves are diuretic and anti-inflammatory and exhibit anti-biofilm activity. They particularly contain flavonoids; Glycosides, Saponins, Tannins and Terpene derivate [15]. According to Heßdörfer and Kunter, preparations containing mustard oils have an antibiotic, broad antibacterial effect in the prevention and are also effective in resistant pathogens [16, 17]. "Meanwhile, experimental evidence has been established for therapeutic effect even in the case of plant-based products. Thus, cranberry products not only influence the adhesive characteristics of uropathogenic E. coli, but also their mobility [14]". For the stabilisation of the local physiological flora, the compensation of oestrogen deficit and the lactobacillus flora is recommended [18, 19]. The administration of L-Methionine three to six 
times 500mg tablets $\left(\right.$ Acimethin $^{\circledR}$ ) can effect urine acidification to a $\mathrm{pH}$ value of between 5.8 and 6.2 [20, 21].

\section{REFFERENCE}

1. https://www.awmf.org/fileadmin/user_upload/Leitl inien/029_AWMF-AK_Krankenhaus-

_und_Praxishygiene/HTML-Dateien/0290071_S1_Harndrainage_2015-02. htm 01.03.2019

2. Liedl, B. (2015). Katheterassoziierte Harnwegsinfektionen CME Zertifizierte Fortbildung. Catheter-associated urinary tract infection CME certified advance training. In: Der Urologe 1305-1306. Springer Verlag. Berlin and Heidelberg.

3. Norsworthy, A. N., Pearson, M. M. (2017). From Catheter to Kidney Stone: The Uropathogenic Lifestyle of Proteus mirabilis. In: Trends in Microbiology, 304-315.

4. Bublak, R. (2016). Der Dauerkatheter als Problemschlauch. The permanent catheter as problem hose In: URO-NEWS p. 17. Springer Verlag.

5. https://www.awmf.org/uploads/tx_szleitlinien/0430481_S2k_Management_IK_

Neurogene_Blasenfunktionsst\%C3\%B6run gen_2016-10.pdf 09.04.2019

6. Getliffe, K. A., Hughes, S. C., Le Claire, M. (2000). The dissolution of urinary catheter encrustation. In: BJU International, 60-64.

7. Liedl, B. (2017). Katheterassoziierte Harnwegsinfekte. Catheter-associated urinary tract infections. In: Procare p. 28-34. Springer Verlag. Heidelberg.

8. Bundesgesundheitsblatt Federal health gazette. (2015). Prävention und Kontrolle Katheterassoziierter Harnwegsinfektionen. Prevention and control of catheter-associated urinary tract infections. Springer Verlag. Heidelberg; 641-650.

9. Madersbacher, S., Stoces, U. Infektiöse Komplikationen des Katheterismus. Infectious complications of catheterisation. In: Das Medizinprodukt; 2016; 9.

10. Hühner, W. (2015). Gestörte Blasenentleerung. Impaired bladder vacation. In: ÄRZTEMAGAZIN Sonderdruck; 6.

11. Blaak, J. (2012). Dehydrierung und Hydratation Studie belegt: Trockene Altershaut braucht saure Pflegeprodukte. Dehydration and hydration study proves: Dry aged skin needs sour care products In: Heilberufe. Das Pflegemagazin; 29-32.

12. Proksch, E., Weidinger, P. (2011). Neue Erkenntnisse zur Pathogenese der empfindlichen Haut. New findings on the pathogenesis of sensitive skin. In: Hautarzt. Springer Verlag. Heidelberg; 900-905

13. Radmayr, C. (2012). Individuelle Pflege des Dauerblasenkatheters. Individual care of permanent bladder catheter. In: ProCare spezial. Springer Verlag; 18-19.

14. Magistro, G.; Scherberich, J. E., Bogner, J. R., Schubert, S., Stief, C. G., Gratzke, C. (2013). Leitliniengerechte Behandlung. Unkomplizierte bakterielle Harnwegsinfektionen. Treatment according to guideline. Uncomplicated bacterial urinary tract infection. In: URO-NEWS. Springer Verlag; 36-42.

15. Kraft, K. (2014). Neue Aspekte zur Wirkung von Phytotherapie bei Harnwegsinfektionen. New aspects to the effect of phyto-therapy in urinary tract infections. In: Phytotherapie; 106-110. Haug Verlag. Stuttgart.

16. Heßdörfer, E. (2012). Harnwegsinfekte - so häufig, so viele Kontroversen. Urinary tract infections - so frequent, so many controversies. In: URO-NEWS; 26-27. Springer Verlag.

17. Kunter, U. (2018). Harnwegsinfekte bei älteren Patienten. Urinary tract infection in elderly patients.In: Der Nephrologe; 32-39. Springer Verlag.

18. Eisenmenger, M. (2018). Antibiotika nur zur Prophylaxe? Rezidivierende Harnwegsinfekte der Frau. Antibiotics only as prophylaxis? Recurring urinary tract infection of women. In: Arzt \& Praxis; 41-45.

19. Stiefelhagen, P. (2018). Harnwegsinfektionen. Bei Diabetikern immer potenziell lebensbedrohlich. Urinary tract infection. Always potentially lifethreatening in diabetics. In: ProCare; 18-19. Springer Verlag.

20. https://nurses.uroweb.org/guideline/catheterisationindwelling-catheters-in-adults-urethral-andsuprapubic/ 01.03.2019

21. Fünfstück, R., Wagenlehner, F. M. E., Ölschläger, T., Naber, K. G. (2012). Harnwegsinfektionen: Zystitis, Pyelonephritis, Urosepsis. Urinary tract infections: cystitis, pyelonephritis, urosepsis. In: DMW Deutsche Medizinische Wochenschrift Thieme Verlag. Stuttgart; 198- 201. 